\title{
Assessment of biomass and carbon content in a Mediterranean Aleppo pine forest using ALS data
}

\author{
Antonio Luis Montealegre ${ }^{1, *}$, María Teresa Lamelas ${ }^{1,2 \dagger}$, Juan de la Riva ${ }^{1, \dagger}$, Alberto García- \\ Martín $^{1,2, \dagger}$ and Francisco Escribano ${ }^{2}$
}

1 GEOFOREST-IUCA research group, Department of Geography, University of Zaragoza, Pedro Cerbuna 12, 50009, Zaragoza, Spain; E-Mail: tlamelas@unizar.es (M.T.L.); delariva@unizar.es (J.R.); algarcia@unizar.es (A.G.)

2 Centro Universitario de la Defensa de Zaragoza, Academia General Militar, Ctra. de Huesca s/n, 50090, Zaragoza, Spain; E-Mail: fescrib@unizar.es (F.E.)

$\dagger$ These authors contributed equally to this work.

* Author to whom correspondence should be addressed; E-Mail: monteale@unizar.es;

Tel.: +34-876-554-058; Fax: +34-976-761-506.

Published: 22 June 2015

\begin{abstract}
Tree biomass estimate is essential for carbon accounting, bioenergy feasibility studies and forest sustainable management. However, little research has been conducted focusing on the use of Airborne Laser Scanning (ALS) technology in Mediterranean Aleppo pine forest. Thus, the availability of ALS information provided by the Spanish National Plan for Aerial Orthophotography (PNOA) determined the main objective of this research. It is our aim to test the suitability of the low point density, discrete, multiplereturn, ALS data, to estimate and map the total biomass (TB) and its carbon content in Pinus halepensis Mill. forest. Accordingly, TB was calculated in 45 field plots, located north-eastern Spain, using allometric equations. This information was related through a multivariate linear regression analysis with a collection of independent variables extracted from the ALS data. The predictive model was validated using a leave-one-out crossvalidation (LOOCV) technique. Then, a regular grid with cell size $25 \mathrm{~m}$ x $25 \mathrm{~m}$ was generated in order to compute TB at stand level. Afterwards, biomass was transformed to carbon content by using a conversion factor. Maximum height, kurtosis and percentage of returns above $1 \mathrm{~m}$ were the ALS metrics included in the fitted model, which presented a $\mathrm{R}^{2}$ value of 0.89 .
\end{abstract}


Keywords: Airborne laser scanning; LiDAR; total biomass; carbon stock; forest inventory; multivariate linear regression; Mediterranean forest

\section{Introduction}

In the last decades, operational collection of information on relevant characteristics of forest ecosystems by means of pure ground-based field inventories has been revolutionized by the development of remote sensing sensors [1]. Optical and radar remote sensing have been widely used to map forest structural attributes and biophysical parameters [2-5]. In this sense, Light Detection and Ranging (LiDAR) has emerged as a promising techniques in forest attribute estimation [1,6,7]. Most commercial LiDAR systems are small-footprint, discrete-return airborne lasers, also referred to as Airborne Laser Scanning (ALS). These systems are able to accurately characterize the threedimensional structure of the forest canopy due to its capacity to record the different reflections of each emitted pulse, corresponding to both, vegetation and terrain beneath it [6,8]. Accordingly, in order to generate a precise Digital Elevation Model (DEM), it is necessary to filter the ALS data and to interpolate the points classified as ground. These DEMs are needed to normalize the heights of the ALS point cloud with respect to the terrain heights [9-11].

Nowadays, the most common methodology in forestry is the area-based one [12-14,1]. In this approach, attributes such as mean height, mean diameter, squared mean diameter, stand basal area, timber volume, stand density or biomass [15-24] are computed at stand level and statistical related to a pool of potential ALS-based predictor variables [14]. In this regard, correlations of moderate to high strength have been found between ALS metrics and the aforementioned dasometric attributes [1].

Particularly, forest biomass mapping has gained interest in recent years due to the following three reasons: i) the relevant role of forests in the carbon cycle and in the balance of greenhouse gases emissions, ii) the assessment of the available resources for bioenergy production and iii) the sustainable management of forests [25]. The total biomass (TB) refers to the dry weight of the plant material from trees, including roots, stems, bark, branches and leaves from the ground to the apex [1]. Conventional methods used to estimate this variable are based on field measurements. However, these methods are limited by the high cost of such destructive sampling, necessary to create allometric models required to extrapolate the results. Alternatively, remote sensing has allowed forest biomass mapping in a wide range of spatial and temporal scales, reducing costs and fieldwork. Numerous studies have correlated the biomass and the spectral response of vegetation using passive optical sensors. However, the results have been typically affected by saturation problems when the biomass is greater than 100 tons/ha [25]. On the other hand, approaches using active sensors such as Synthetic Aperture Radar (SAR) have shown that they are more sensitive to higher levels of biomass and, more recently, the use of ALS technology is becoming a tool with great potential to estimate biomass [26,1]. This fact, together with the availability of ALS data captured for the entire Spanish territory under the National Plan for Aerial Orthophotography (PNOA), has determined the aim of this work, which is to evaluate the suitability of this information to estimate and map TB and carbon content in Pinus halepensis Mill. forest at stand level. Our objective implies developing a statistical model that 
adequately relates the information provided by the ALS data with the one extracted directly from the field.

\section{Methods}

\subsection{Study area}

The study area corresponds to monospecific stands of Pinus halepensis Mill. and it is located in the central Ebro valley (41 $50^{\prime} \mathrm{N}, 0^{\circ} 57^{\prime} \mathrm{W}$ ) (Fig. 2). This river crosses the Autonomous Region of Aragón, sited northeastern Spain. The forest under study is fragmented in stands of variable sizes and occupies 8266 ha. In some areas, Aleppo pine forest is interspersed with evergreen shrubs, dominated by Quercus coccifera L., Juniperus oxycedrus L. subsp. macrocarpa (Sibth. \& Sm.) Ball, and Thymnus vulgaris L. Part of the study area is located inside the Military Training Center (CENAD) "San Gregorio", involving a direct risk of fire. According to the Third Spanish National Forest Inventory (NFI 3), pine forest is the most significant habitat in Autonomous Region of Aragón. In fact, it represents $49.88 \%$ of the forested area. In addition, Aleppo pines play an important role in the protection and restoration of forest as this tree species is practically the only one adapted to the adverse climatic and edaphic conditions of the study area. In this regard, it is important to notice that the study area is characterized by nutrient-poor, gypsiferous soils. In addition, this area presents a hilly topography, with elevations ranging from about $400 \mathrm{~m}$ to $750 \mathrm{~m}$ above sea level. Climate of the region is Mediterranean with continental features, i.e., irregular annual precipitation, cold winters and hot, dry summers [27].

\subsection{ALS data}

The ALS data were provided by the Spanish National Plan for Aerial Orthophotography (PNOA, http://www.ign.es/PNOA/vuelo_lidar.html). The information was captured in several surveys conducted between January and February 2011. A Leica ALS60 sensor was used. This is a smallfootprint, discrete return sensor. Data were delivered in $2 \mathrm{~km}$ x $2 \mathrm{~km}$ tiles of unclassified points in LAS binary file, format v. 1.2, containing $x, y, z$ coordinates (UTM Zone 30 ETRS 1989), with up to four returns recorded per pulse. The flying height of the ALS mission was around 3,000 m.a.g.l. The sensor was operating in $1.064 \mu \mathrm{m}$ wavelength, $0.22 \mathrm{mrad}$ beam divergence and $\pm 29 \mathrm{scan}$ angle degrees. The resulting ALS point density for the study area was 1 point $/ \mathrm{m}^{2}$ with a vertical accuracy higher than 0.20 $\mathrm{m}$.

After eliminating the noise of the point cloud, it was necessary to perform a filtering process to identify ground returns. The classification algorithm implemented in the MCC software 2.1, developed by Evans and Hudak [28], was applied. This algorithm was selected given its good performance in hilly forest landscapes [9]. Points classified as ground were interpolated using the "Point-TIN-Raster" interpolation method [29] in ArcGIS 10.2 software (ESRI, Redlands, CA, USA) to create a DEM. This model, with $1 \mathrm{~m}$ spatial resolution, was used to normalize the heights of the point cloud. Then, using the "ClipData" and "CloudMetrics" commands implemented in FUSION LDV 3.30 software [30], several ALS point cloud metrics commonly used in vegetation structure modeling were calculated at each plot. A threshold of $1 \mathrm{~m}$ above the ground was applied in the selection of the points used in the 
calculation in order to exclude from the metrics the returns belonging to bare-earth and understory [31].

\subsection{Field data}

The fieldwork campaign was conducted between July and September 2014. The location of 45 circular plots with $15 \mathrm{~m}$ radius was selected via a stratified random sampling, trying to obtain a representative sample of the variability of forest height and topographic complexity [31]. The selected sites were staked out in field using a Leica VIVA GS15 CS10 real-time kinematic Global Navigation Satellite System, achieving an average planimetric accuracy of $0.15 \mathrm{~m}$. The total tree height $(h)$ was measured using a Vertex instrument for precision height (Haglöf Sweden $\left.{ }^{\circledR}\right)$. In addition, the tree diameter at breast height $(d b h)$, considering the standard height of $1.3 \mathrm{~m}$ used in Europe, was measured using a calliper Haglöf Mantax Precision Blue (Haglöf Sweden®). In total 2,063 trees were inventoried (only trees greater than $7.5 \mathrm{~cm} d b h$ ). The different biomass fractions at each plot was calculated using the Pinus halepensis Mill allometric models reported by Ruiz-Peinado et al. [32] (equations 1, 2, 3, 4 and 5):

$$
\text { Ws }=0.0139 \cdot \mathrm{dbh}^{2} \cdot \mathrm{h}
$$

$\mathrm{W}_{\mathrm{b} 7}=[3.926 \cdot(\mathrm{dbh}-27.5)] \cdot \mathrm{Z}$; If $\mathrm{dbh} \leq 27.5 \mathrm{~cm}$ then $\mathrm{Z}=0 ;$ If $\mathrm{dbh}>27.5 \mathrm{~cm}$ then $\mathrm{Z}=1$

$$
\begin{gathered}
\mathrm{W}_{\mathrm{b} 2-7}=4.257+0.00506 \cdot \mathrm{dbh}^{2} \cdot \mathrm{h}-0.0722 \cdot \mathrm{dbh} \cdot \mathrm{h} \\
\mathrm{W}_{\mathrm{b} 2+\mathrm{n}}=6.197+0.00932 \cdot \mathrm{dbh}^{2} \cdot \mathrm{h}-0.0686 \cdot \mathrm{dbh} \cdot \mathrm{h} \\
\mathrm{W}_{\mathrm{r}}=0.0785 \cdot \mathrm{dbh}^{2}
\end{gathered}
$$

Where $W s$ is the biomass weight of the stem fraction $(\mathrm{kg}), W b 7$ is the biomass weight of the thick branch fraction (diameter larger than $7 \mathrm{~cm})(\mathrm{kg}), W_{b 2-7}$ is the biomass weight of medium branch fraction (diameter between 2 and $7 \mathrm{~cm})(\mathrm{kg}), W_{b 2+n}$ is the biomass weight of thin branch fraction (diameter smaller than $2 \mathrm{~cm}$ ) with needles $(\mathrm{kg})$, and $\mathrm{W}_{\mathrm{r}}$ is the biomass weight of the belowground fraction $(\mathrm{kg})$.

The results of these equations were aggregated to calculate the TB in kilograms of each tree in the field plot, in order to extrapolate the TB values from sample plots to per hectare biomass value ( $\mathrm{kg}$ of dry biomass per ha).

\subsection{Predictive model for estimating the $T B$}

Following Means et al. [12], Næsset [13], Gonzalez-Ferreiro et al. [11] and García et al. [10], a multivariate linear regression approach was adopted in order to develop a model able to estimate the TB. The statistical analysis was performed in the $R$ environment (http://www.r-project.org/). Given the large number of potential ALS-derived metrics, the Spearman's rank correlation coefficient (Rho) was previously applied in order to select those independent variables with the strongest correlation coefficient with TB [22]. Then, the selected variables were included in a stepwise regression, trying to develop a parsimonious model in order to avoid over-fitting [33,34]. Predictor variables with a 
significance value of partial $F$ statistic greater than 0.05 were removed from the model [31]. Besides, the fitted model was selected in compliance with the statistical assumptions of linearity, normality of the residuals, homoscedasticity, and independence or no autocorrelation [10].

A leave-one-out cross-validation (LOOCV) technique was applied with the purpose of performing an unbiased assessment of the predictive capacity of the model [14]. The model goodness-of-fit was assessed comparing the adjusted coefficient of determination $\left(\mathrm{R}^{2}\right)$, the root-mean-square error (RMSE) and the mean of the residuals obtained from LOOCV technique [35]. The final model was obtained by averaging the model coefficients computed at each step of the cross-validation performed [14].

\subsection{Mapping TB and carbon content}

The pixel size selected to compute the ALS-derived metrics and to map TB was $25 \mathrm{~m}$ x $25 \mathrm{~m}$, representing an area of $625 \mathrm{~m}^{2}$, similar to the field plot dimensions $\left(706.86 \mathrm{~m}^{2}\right)$. Metrics involved in the equation of the TB model were obtained using the "GridMetrics" and "CSV2Grid" commands implemented in FUSION LDV 3.30 [30]. Then, using map algebra in ArcGIS 10.2 (ESRI, Redlands, CA, USA), model coefficients were applied to the raster layers to achieve a TB map at stand level. Finally, TB values were converted to carbon content using a conversion factor of 0.499 following Montero et al. [36].

\section{Results and Discussion}

A summary of the variables estimated in the field is presented in Table 1. Terrain slope in the plots averaged $10.7^{\circ}$ and ranged from 0.7 to $25.7^{\circ}$. As can be observed, structural variables related to Aleppo pine forest show a remarkable variability. Inventoried trees range from smaller trees (heights of $3.7 \mathrm{~m}$ and stem diameters of $8.6 \mathrm{~cm}$ ) to bigger ones (heights of $11.3 \mathrm{~m}$ and stem diameter of 28.3 $\mathrm{cm}$ ). This implies a subsequent variability in biomass estimations from these variables, as can be seen in standard deviation values of aboveground biomass (AGB), Wr and TB.

Table 1. Summary of the field plot data $(n=45)$.

\begin{tabular}{llllll}
\hline & Min & Max & Range & Mean & Standard deviation \\
\hline Slope (degrees) & 0.7 & 25.7 & 25.0 & 10.7 & 7.2 \\
Tree height $(\mathrm{m})$ & 3.7 & 11.3 & 7.6 & 7.1 & 2.0 \\
$d b h(\mathrm{~cm})$ & 8.6 & 28.3 & 19.7 & 15.2 & 4.7 \\
AGB: Aboveground biomass (kg/ha) & 989.2 & $112,076.4$ & $111,087.2$ & $37,462.6$ & $27,879.5$ \\
Wr: Belowground biomass (kg/ha) & 423.4 & $32,701.5$ & $32,278.2$ & $13,237.4$ & $7,435.3$ \\
TB: Total biomass (kg/ha) & $1,412.6$ & $144,777.9$ & $143,365.3$ & $50,700.0$ & $35,123.8$ \\
Carbon content (kg/ha) & 704.9 & $72,244.2$ & $71,539.3$ & $25,299.3$ & $17,526.8$ \\
\hline
\end{tabular}

Table 2 shows the Spearman correlation coefficients obtained for each of the ALS-derived metrics. TB is strongly correlated to the upper ALS height percentiles, particularly with the $\mathrm{P}_{25}$ to $\mathrm{P}_{60}(0.95$ in all of them), being positive in all cases. The greater the height of the trees within the plot the greater the TB value as the stems and branches are more developed. The same interpretation presents the canopy height metrics, such maximum (0.88), mean (0.95) and mode elevation (0.92). In the case of metrics related to the variability of canopy height, the skewness of the height distribution of the returns, which describes the degree of concentration of heights around high or low values, i.e., 
provides some indication of how asymmetric the point distribution is, presents an inverse Spearman's correlation coefficient (-0.83). On the contrary, the standard deviation and variance, both with Rho values of 0.71 , show the dispersion of point height values data around the mean height. Thus, the higher the TB the more dispersion of the data concerning the average height value because the trees are bigger. Finally, metrics related to canopy density correlate strongly with TB, particularly the percentage of first returns above mean height (0.88) and the ratios of all returns above mean and $1 \mathrm{~m}$ ( 0.88 and 0.84 , respectively). The interpretation of such metrics is similar, as ratios express the proportion of returns belonging either to the canopy surface (first returns) or the whole canopy (all returns).

Table 2. Correlation coefficients (Rho) describing the strength of linear relationships between plotderived TB and ALS-derived metrics. ${ }^{* *}$ and ${ }^{*}$ denote significance $(\mathrm{P}$-value $<0.01$ and 0.05 , respectively); ${ }^{\mathrm{ns}}$ denote not significant $(\mathrm{P}$-value $>0.05)$.

\begin{tabular}{llll}
\hline Variable & Rho & Variable & Rho \\
Canopy height percentiles metrics & & Canopy height variability metrics & \\
$\mathrm{P}_{01}$ & $0.43^{* *}$ & Elev. standard deviation (SD) & $0.71^{* *}$ \\
$\mathrm{P}_{05}$ & $0.67^{* *}$ & Elev. variance & $0.71^{* *}$ \\
$\mathrm{P}_{10}$ & $0.85^{* *}$ & Elev. coefficient of variation (CV) & $-0.37^{* *}$ \\
$\mathrm{P}_{20}$ & $0.94^{* *}$ & Elev. interquartile range (IQ) & $0.54^{* *}$ \\
$\mathrm{P}_{25}$ & $0.95^{* *}$ & Elev. skewness & $-0.83^{* *}$ \\
$\mathrm{P}_{30}$ & $0.95^{* *}$ & Elev. kurtosis & $0.50^{* *}$ \\
$\mathrm{P}_{40}$ & $0.95^{* *}$ & Canopy density metrics & \\
$\mathrm{P}_{50}$ & $0.95^{* *}$ & $\%$ first returns above $1 \mathrm{~m}$ & $0.83^{* *}$ \\
$\mathrm{P}_{60}$ & $0.95^{* *}$ & $\%$ all returns above $1 \mathrm{~m}$ & $0.65^{* *}$ \\
$\mathrm{P}_{70}$ & $0.94^{* *}$ & $\%$ first returns above mean height & $0.88^{* *}$ \\
$\mathrm{P}_{75}$ & $0.94^{* *}$ & $\%$ first returns above mode height & $0.40^{* *}$ \\
$\mathrm{P}_{80}$ & $0.94^{* *}$ & $\%$ all returns above mean height & $0.79^{* *}$ \\
$\mathrm{P}_{90}$ & $0.93^{* *}$ & $\%$ all returns above mode height & $0.18^{\text {ns }}$ \\
$\mathrm{P}_{95}$ & $0.90^{* *}$ & (All returns above $1 \mathrm{~m}) /($ Total first returns) $\cdot 100$ & $0.84^{* *}$ \\
$\mathrm{P}_{99}$ & $0.89^{* *}$ & & \\
Canopy height metrics & & (All returns above mean) / (Total first returns) $\cdot 100$ & $0.88^{* *}$ \\
Elev. minimum & $0.10^{\text {ns }}$ & & \\
Elev. maximum & $0.88^{* *}$ & (All returns above mode) / (Total first returns) $\cdot 100$ & $0.40^{* * *}$ \\
Elev. mean & $0.95^{* *}$ & & \\
Elev. mode & $0.92^{* *}$ & & \\
\hline
\end{tabular}

Table 3 shows the summary of the selected model for estimating TB that includes three types of ALS metrics: i) the maximum elevation, ii) the kurtosis of the height distribution of the returns, and iii) the percentage of all returns above $1 \mathrm{~m}$. As can be seen in Figure 1 and Table 2, the relationship between TB and these variables is direct. The higher the value of these metrics, the larger the amount of points returning from trees, implying an increase in timber volume per hectare and in plant material.

As shown in Table 3, the model presented a $\mathrm{R}^{2}$ of 0.89 , a RMSE of 11,327.69 and a RMSEcv of $11,418.11 \mathrm{~kg} / \mathrm{ha}$. The bias value of 0.12 evidences a slightly model overestimation. 
Table 3. Model summary for estimating TB.

\begin{tabular}{|c|c|c|c|c|c|c|c|}
\hline \multirow{2}{*}{$\begin{array}{c}\text { Dependent } \\
\text { variable }\end{array}$} & \multirow{2}{*}{ Predictive model } & \multicolumn{3}{|c|}{ Fitting phase } & \multicolumn{3}{|c|}{ Cross-validation } \\
\hline & & $\mathbf{R}^{2}$ & RMSE & Bias & $\mathbf{R}^{2}$ & RMSEcv & Bias \\
\hline TB (kg/ha) & $\begin{array}{l}-70277.86+8902.59 \cdot \text { Elev. maximum } \\
+8232.54 \cdot \text { Elev. kurtosis }+563.10 \cdot \% \text { all } \\
\text { returns above } 1 \mathrm{~m}\end{array}$ & 0.89 & $11,327.69$ & 0.00 & 0.89 & $11,418.11$ & 0.12 \\
\hline
\end{tabular}

Figure 1. Metrics associated to the vertical distribution of ALS returns in three selected field plots representative of the study area: (a) Low height, (b) medium height and (c) great height Aleppo pines.

(a)
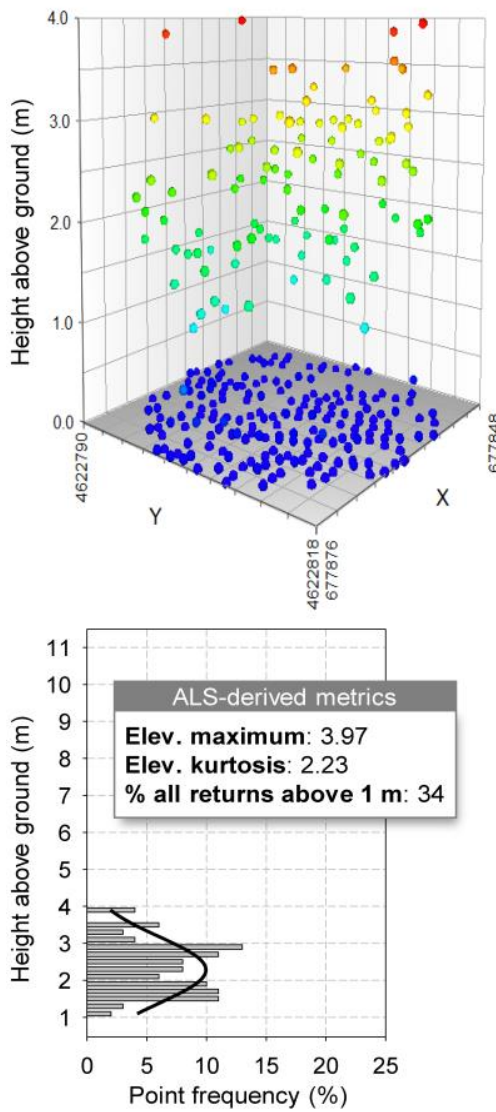

\section{Field plot data}

TB (kg/ha): $14,798.94$ AGB $(\mathrm{kg} / \mathrm{ha}): 10,200.13$ $\mathbf{W}_{\mathrm{r}}(\mathrm{kg} / \mathrm{ha}): 4,598.81$ (b)
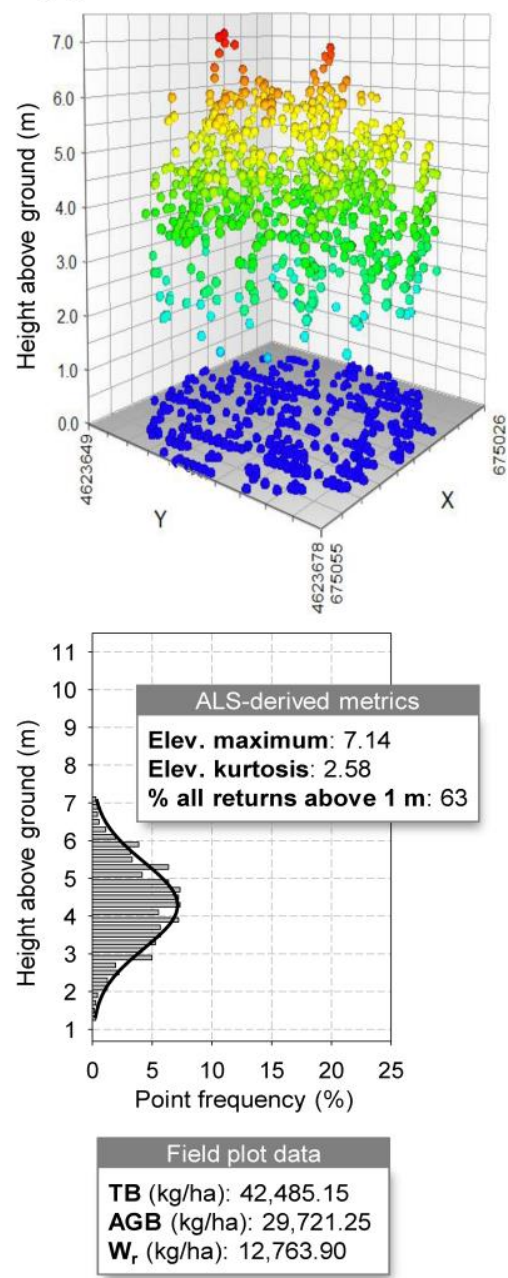

(c)
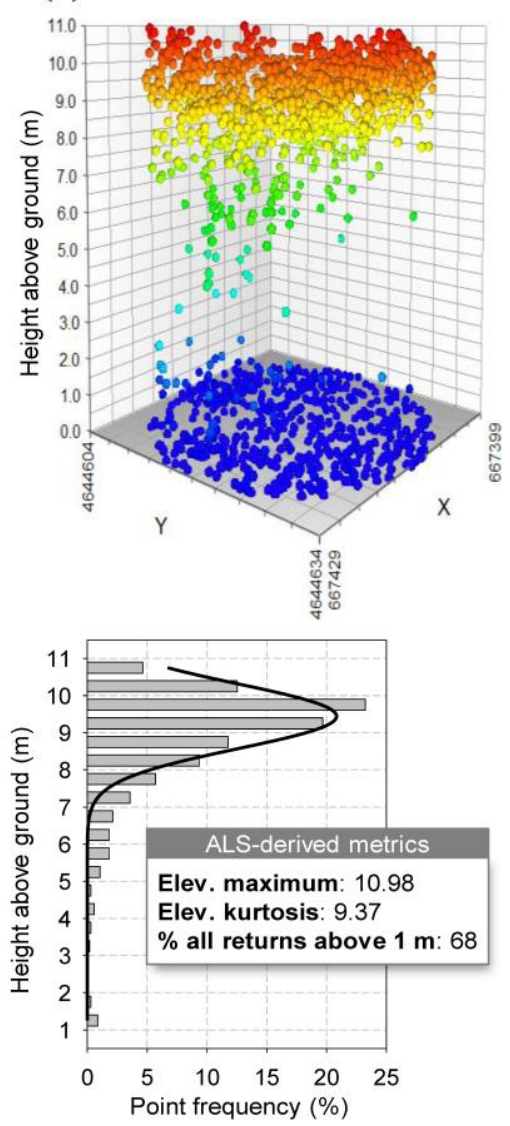

TB (kg/ha): $144,777.94$ AGB $(\mathrm{kg} / \mathrm{ha}): 29,721.25$ $\mathbf{W}_{\mathbf{r}}(\mathrm{kg} / \mathrm{ha}): 12,763.90$

Figure 2 shows the TB and carbon content mapping after implementation of the prediction model in a GIS environment.

The results of this study indicate that LiDAR-PNOA data can be used to estimate the TB in monospecific Pinus halepensis Mill. forest stands. The good fit of the model obtained reveals, not only the suitability of the methodology, but also the correlation between the statistics obtained from ALS point cloud and the $h$ and $d b h$ measured in the field. Although the RMSE above 11,000 kg/ha may seem high, it should be noted that the inventory data covered a wide range of values as can be observed in Table 1. 
Figure 2. Map of the TB and carbon content in two selected areas of the study site. (a) Heterogeneous Aleppo pine forest with lower stand density. (b) Includes two distinct homogeneous areas, differentiated by stand density and canopy height.
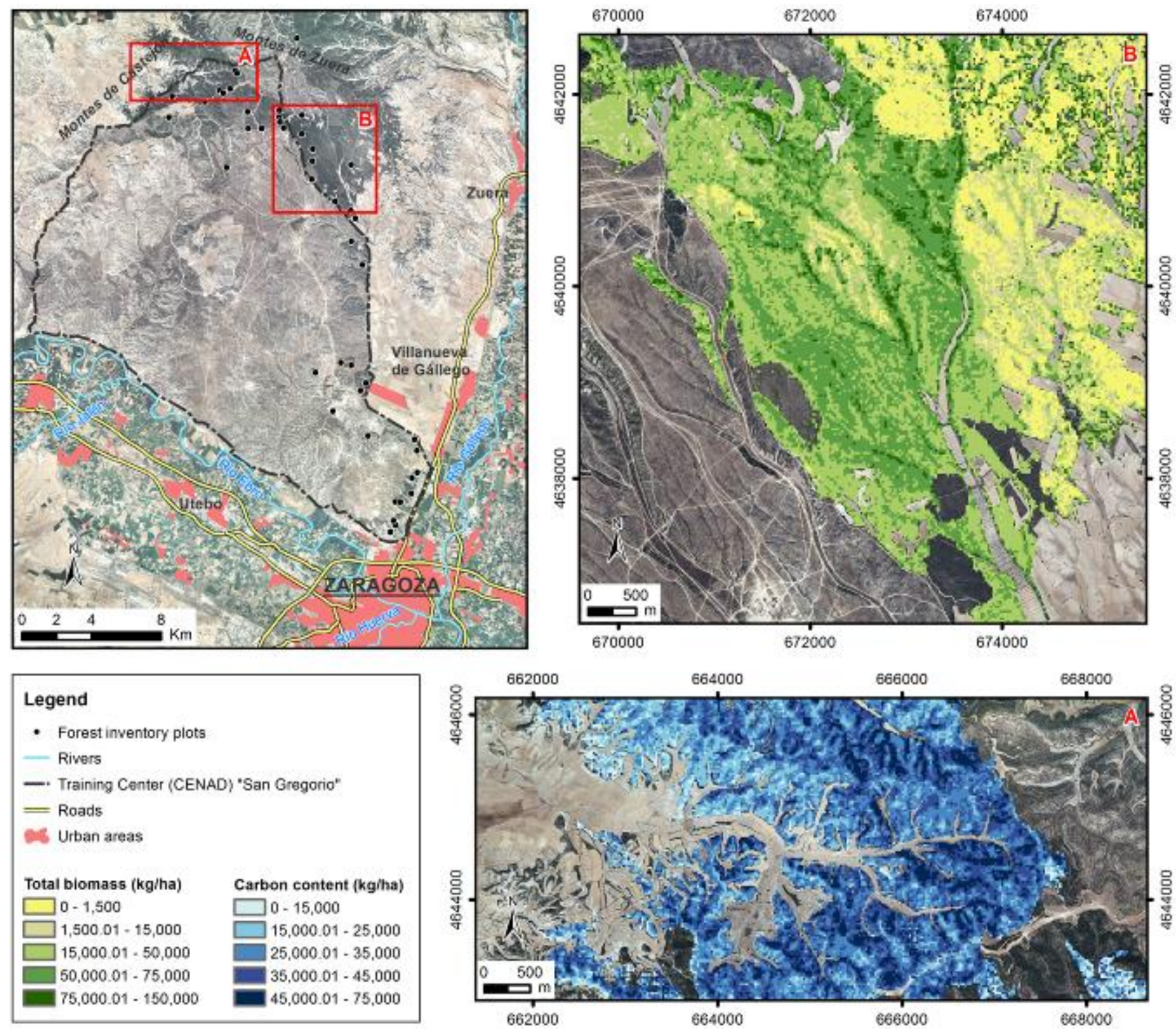

It is important to notice that both, the $\mathrm{R}^{2}$ and RMSE value match those obtained by other authors, such as González-Ferreiro et al. [11]. In contrast to other studies, such as García et al. [25], it was not necessary to perform a logarithmic transformation of the original variables in order to achieve a better fit of the model or to meet the assumptions of the linear regression model.

ALS metrics included in the model behave logically as can be observed in Figure 1. In this regard, it is common that prediction models include ALS-derived metrics directly related to the canopy height, variables characterizing the variability, dispersion and shape of the height distribution of returns, as is the case of kurtosis, and variables related to the canopy density and tree cover, as the percentage of all returns above $1 \mathrm{~m}$.

On the other hand, the no contemporaneity of the ALS data acquisition and the field campaign was considered irrelevant, as no significant changes in forest structure occurred in that time lapse. 
Furthermore, the low point density of the data did not affect the existence of high and significant correlations between TB derived from field data and ALS-derived metrics.

In the future, it would be advisable to analyze the possibility of estimating forest biomass disaggregated in different fractions (stem, branches, leaves and roots) in order to model the carbon storage in detail and improve forest stand management. Besides, it would be desirable to study the usefulness of the PNOA-LiDAR data to characterize other forest species in large areas, as it could increase the accuracy of the results and reduce the costs with respect to traditional inventories.

\section{Conclusions}

Active remote sensing with ALS technology brings a new perspective to forest inventories providing 3-D information of the vegetation structure, as well as an improvement in the accuracy of the results and a reduction in costs. In this regard, the benefit of estimating the TB is even bigger, as with this methodology systematic sampling destructive procedures are not necessary. This work has proved the usefulness to estimate TB and carbon content in monospecific Aleppo pine stands representative of the continental Mediterranean climate. In the light of the results obtained, the adopted methodology was suitable. Our results match those achieved in other types of forests. Considering that PNOA project will presumably produce more LiDAR products in the next years, it would be desirable to evaluate the adequacy of the generated model to future captures of data and to develop new models of biomass components as well as in other types of Mediterranean forests.

\section{Acknowledgments}

This work has been financed by the Government of Aragón, Department of Science, Technology and University (FPI Grant BOA 30, 11/02/2011) and supported by the Research Project of Centro Universitario de la Defensa de Zaragoza (Project No: 2013-04). The ALS data were provided by the Spatial Information Centre of Aragón. The authors are grateful to the Training Center (CENAD) "San Gregorio" for its assistance in the field and for the invaluable technical support.

\section{Author Contributions}

M.T. Lamelas had the original idea for the study. Antonio L. Montealegre, M.T. Lamelas, A. García-Martín, J. de la Riva and F. Escribano conducted the fieldwork campaign. Antonio L. Montealegre, M.T. Lamelas, J. de la Riva and A. García-Martín developed the methodology and performed the analysis and Antonio L. Montealegre wrote the manuscript, incorporating suggestions from all co-authors, who approved the final manuscript.

\section{Conflicts of Interest}

The authors declare no conflict of interest.

\section{References}

1. Maltamo, M.; Næsset, E.; Vauhkonen, J. Forestry Applications of Airborne Laser Scanning: Concepts and Case Studies. Springer London, UK, 2014; p. 464. 
2. Chuvieco, E. Earth Observation of Wildland Fires in Mediterranean Ecosystems. Springer Alcalá de Henares, Spain, 2009; p. 257.

3. Le Toan, T.; Beaudoin, A.; Riom, J.; Guyon, D. Relating forest biomass to SAR data. Geoscience and Remote Sensing, IEEE Transactions on 1992, 30 (2), 403-411.

4. Leboeuf, A.; Fournier, R.A.; Luther, J.E.; Beaudoin, A.; Guindon, L. Forest attribute estimation of northeastern Canadian forests using QuickBird imagery and a shadow fraction method. Forest Ecology and Management 2012, 266 (0), 66-74.

5. Tanase, M.; de la Riva, J.; Santoro, M.; Pérez-Cabello, F.; Kasischke, E. Sensitivity of SAR data to post-fire forest regrowth in Mediterranean and boreal forests. Remote Sensing of Environment 2011, 115 (8), 2075-2085.

6. Vosselman, G.; Maas, H.-G. Airborne and Terrestrial Laser Scanning. Whittles Publishing Dunbeath, UK, 2010; p. 320.

7. Lefsky, M.A.; Cohen, W.B.; Parker, G.G.; Harding, D.J. Lidar Remote Sensing for Ecosystem Studies. BioScience 2002, 52 (1), 19-30.

8. Kraus, K.; Pfeifer, N. Determination of terrain models in wooded areas with airborne laser scanner data. ISPRS Journal of Photogrammetry and Remote Sensing 1998, 53 (4), 193-203.

9. Montealegre, A.L.; Lamelas, M.T.; Tanase, M.; de la Riva, J. Forest Fire Severity Assessment Using ALS Data in a Mediterranean Environment. Remote Sensing 2014, 6 (5), 4240-4265.

10. García, D.; Godino, M.; Mauro, F. Lidar: Aplicación Práctica Al Inventario Forestal. Editorial Académica Española Lexington, USA, 2012; p. 196.

11. Gonzalez-Ferreiro, E.; Dieguez-Aranda, U.; Miranda, D. Estimation of stand variables in Pinus radiata D. Don plantations using different LiDAR pulse densities. Forestry 2012, 85, 281 - 292.

12. Means, J.; Acker, S.; Fitt, B.; Renslow, M.; Emerson, L.; Hendrix, C. Predicting forest stand characteristics with airborne scanning LiDAR. Photogrammetric Engineering and Remote Sensing 2000, 66 (11), 1367 - 1371.

13. Næsset, E. Predicting forest stand characteristics with airborne scanning laser using a practical two-stage procedure and field data. Remote Sensing of Environment 2002, 80 (1), 88-99.

14. Bouvier, M.; Durrieu, S.; Fournier, R.A.; Renaud, J.-P. Generalizing predictive models of forest inventory attributes using an area-based approach with airborne LiDAR data. Remote Sensing of Environment 2015, 156 (0), 322-334.

15. Magnussen, S.; Eggermont, P.; LaRiccia, V. N. Recovering Tree Heights from Airborne Laser Scanner Data. Forest Science 1999, 45 (3), 407-422.

16. Næsset, E.; Bjerknes, K.-O. Estimating tree heights and number of stems in young forest stands using airborne laser scanner data. Remote Sensing of Environment 2001, 78 (3), 328-340.

17. Holmgren, J.; Nilsson, M.; Olsson, H. Estimation of Tree Height and Stem Volume on Plots Using Airborne Laser Scanning. Forest Science 2003, 49 (3), 419-428.

18. Hall, S.A.; Burke, I.C.; Box, D.O.; Kaufmann, M.R.; Stoker, J.M. Estimating stand structure using discrete-return lidar: an example from low density, fire prone ponderosa pine forests. Forest Ecology and Management 2005, 208 (1-3), 189-209.

19. Coops, N.; Hilker, T.; Wulder, M.; St-Onge, B.; Newnham, G.; Siggins, A.; Trofymow, J. Estimating canopy structure of Douglas-fir forest stands from discrete-return LiDAR. TreesStructure and Function 2007, 21, 295 - 310. 
20. Næsset, E.; Gobakken, T.; Holmgren, J.; Hyyppä, H.; Hyyppä, J.; Maltamo, M.; Nilsson, M.; Olsson, H.; Persson, Å.; Söderman, U. Laser scanning of forest resources: the nordic experience. Scandinavian Journal of Forest Research 2004, 19 (6), 482-499.

21. Treitz, P.; Lim, K.; Woods, M.; Pitt, D.; Nesbitt, D.; Etheridge, D. LiDAR Sampling Density for Forest Resource Inventories in Ontario, Canada. Remote Sensing 2012, 4 (4), 830-848.

22. Watt, M.; Meredith, A.; Watt, P.; Gunn, A. Use of LiDAR to estimate stand characteristics for thinning operations in young Douglas-fir plantations. New Zealand Journal of Forestry Science 2013, 43 (1), 18.

23. Zhao, K.; Popescu, S.; Nelson, R. Lidar remote sensing of forest biomass: A scale-invariant estimation approach using airborne lasers. Remote Sensing of Environment 2009, 113 (1), $182-$ 196.

24. Næsset, E.; Gobakken, T. Estimation of above- and below-ground biomass across regions of the boreal forest zone using airborne laser. Remote Sensing of Environment 2008, 112 (6), 30793090.

25. García, M.; Riaño, D.; Chuvieco, E.; Danson, F.M. Estimating biomass carbon stocks for a Mediterranean forest in central Spain using LiDAR height and intensity data. Remote Sensing of Environment 2010, 114 (4), 816-830.

26. Vosselmann, G.; Maas, H.G. Airborne and terrestrial laser scanning. Whittles Publishing Dunbeath, UK, 2010; p. 318.

27. Vicente-Serrano, S.M.; Lasanta, T.; Gracia, C. Aridification determines changes in forest growth in Pinus halepensis forests under semiarid Mediterranean climate conditions. Agricultural and Forest Meteorology 2010, 150 (4), 614-628.

28. Evans, J.S.; Hudak, A.T. A Multiscale Curvature Algorithm for Classifying Discrete Return LiDAR in Forested Environments. Geoscience and Remote Sensing, IEEE Transactions on 2007, 45 (4), 1029-1038.

29. Renslow, M. Manual of Airborne Topographic Lidar. The American Society for Photogrammetry and Remote Sensing Bethesda, USA, 2013; p. 504.

30. McGaughey, R. FUSION/LDV: Software for LIDAR Data Analysis and Visualization, US Department of Agriculture, Forest Service, Pacific Northwest Research Station Seattle, USA, 2009; p. 175.

31. Naesset, E.; Okland, T. Estimating tree height and tree crown properties using airborne scanning laser in a boreal nature reserve. Remote Sensing of Environment 2002, 79 (1), 105 - 115.

32. Ruiz-Peinado, R.; del Rio, M.; Montero, G. New models for estimating the carbon sink capacity of Spanish softwood species. Forest Systems 2011, 20 (1), 176-188.

33. Hair, J.F.; Anderson, R.E.; Tatham, R.L.; Black, W.C. Análisis multivariante. 5th ed.; Prentice Hall Iberia Madrid, Spain, 1999; p. 799.

34. Chen, Q.; Gong, P.; Baldocchi, D.; Tian, Y.Q. Estimating Basal Area and Stem Volume for Individual Trees from Lidar Data. Photogrammetric Engineering \& Remote Sensing 2007, 73 (12), 1355-1365.

35. Andersen, H.-E.; McGaughey, R.J.; Reutebuch, S.E., Estimating forest canopy fuel parameters using LIDAR data. Remote Sensing of Environment 2005, 94 (4), 441-449. 
36. Montero, G.; Ruiz-Peinado, R.; Muñoz, M. Producción de biomasa y fijación de CO2 por los bosques españoles. Instituto Nacional de Investigación y Tecnología Agraria y Alimentaria, Ministerio de Educación y Ciencia Torrejón de Ardoz, Spain, 2005; p. 270.

(C) 2015 by the authors; licensee MDPI, Basel, Switzerland. This article is an open access article distributed under the terms and conditions of the Creative Commons Attribution license (http://creativecommons.org/licenses/by/4.0/). 